\title{
Judgement in artificial eruption of embedded teeth from an oral surgery perspective: review article
}

\author{
Basel Mahardawi ${ }^{1}$, Kumar K C ${ }^{1}$, Kanin Arunakul ${ }^{1}$, Teeranut Chaiyasamut ${ }^{1}$, Natthamet Wongsirichat $^{1,2}$ \\ ${ }^{1}$ Department of Oral and Maxillofacial Surgery, Faculty of Dentistry, Mahidol University, \\ ${ }^{2}$ Consultant of Walailak University International College of Dentistry, Bangkok, Thailand
}

\begin{abstract}
J Korean Assoc Oral Maxillofac Surg 2020;46:12-18)
Impacted teeth are a frequent phenomenon encountered by every clinician. The artificial eruption of embedded teeth is the process of directing an impacted tooth into normal occlusion. This procedure is currently attracting attention, with the aim of finding the best technique to use according to each case. This article presents key information regarding impacted incisors, canines, and premolars. In addition, we describe the most common techniques to use for artificial eruption, the open and closed techniques. We review the literature concerning these techniques and outline how clinicians can manage every type of impacted tooth.
\end{abstract}

Key words: Artificial eruption, Closed technique, Impacted, Open technique

[paper submitted 2019. 3. 15 / accepted 2019. 5. 10]

\section{Introduction}

The normal eruption, position, and morphology of teeth are essential factors of facial esthetics and phonetics, and are the aim of every person to have and every clinician to achieve with their patients. Deviations from normal eruption patterns are frequently observed, and impacted teeth are challenging for clinicians to plan and apply appropriate treatment. It is essential to have a thorough knowledge of eruption disturbances in order to promptly intervene.

When a significant change from the normal shedding process occurs, diagnosis and treatment should be carried out as soon as possible. Alteration of tooth eruption time could be a symptom of a general condition or, in some cases, an indication of altered physiology and craniofacial development ${ }^{1}$.

The process of artificially erupting an impacted tooth

\footnotetext{
Natthamet Wongsirichat

Department of Oral and Maxillofacial Surgery, Faculty of Dentistry, Mahidol University, 6 Yothi Street, Rachathewee District, Bangkok 10400, Thailand

TEL: +66-22-007845 FAX: +66-22-007844

E-mail:natthamet.won@mahidol.ac.th

ORCID: https://orcid.org/0000-0003-3005-2680

(2) This is an open-access article distributed under the terms of the Creative Commons Attribution Non-Commercial License (http://creativecommons.org/ licenses/by-nc/4.0/), which permits unrestricted non-commercial use, distribution, and reproduction in any medium, provided the original work is properly cited.

Copyright (C) 2020 The Korean Association of Oral and Maxillofacial Surgeons. All rights reserved.
}

and guiding it into occlusion requires a meticulous multidisciplinary approach, requiring the contributions of an oral surgeon, orthodontist, pedodontist, and in some cases a periodontist. The role of the oral surgeon is to uncover the impacted teeth to aid in the orthodontic treatment, which then guides and aligns those teeth in the dental arch, providing better functional and esthetic results.

\section{Impacted Teeth and Treatment Modalities}

\section{Impacted canines}

Following the mandibular third molars, the maxillary permanent canine is the second most impacted tooth, with a prevalence between $0.3 \%-2.4 \%$ and showing a higher predilection in females than in males ${ }^{3,4}$. Dachi and Howell ${ }^{4}$ indicated that impactions of maxillary canines take place unilaterally in $92 \%$ of the cases, and only $8 \%$ are bilateral. Canines have a higher tendency to be impacted palatally than labially $^{5}$. Impaction of an anterior tooth can lead to functional or esthetic impairment and possibly further complications like midline diastema, crowding, root resorption on the adjacent permanent teeth ${ }^{6}$, and cysts. Therefore, early and accurate diagnosis of an impacted canine is required and the treatment is often directly initiated by elimination of any obstruction 
to the normal path of eruption to provide enough space and proper direction for the underlying canine ${ }^{7}$.

Various procedures in the management of impacted canines are presented. These include the early interceptive approach ${ }^{8}$, surgical exposure of the canine crown followed by orthodontic guidance to the dental $\mathrm{arch}^{9}$, and autogenous tooth transplantation $^{10}$. The canine is a stable arch former and has esthetic value.

If an abnormality cannot be corrected by interceptive treatment alone, both surgical and orthodontic approaches are often considered to guide the impacted canine into normal occlusion. This can be achieved by two main surgical techniques: the open technique and the closed technique.

\section{1) Open technique}

This technique involves gingivectomy and apically positioned flap (also known as apically displaced flap) procedures to expose the impacted tooth. Selection of this procedure is based on a thorough assessment of the labiolingual positioning of the impacted tooth, the vertical position in relation to the mucogingival junction, the mesio-distal position in relation to the lateral incisor, and the amount and type of gingiva surrounding the site of the tooth.

Gingivectomy is performed to expose the clinical crown by removing the gingiva, which covers the coronal portion of the unerupted tooth, while maintaining adequate keratinized gingiva. In some cases removal of the overlying bone is necessary. This is followed by the orthodontic phase to track the tooth into normal occlusion.

The apically displaced flap procedure is conducted by elevating a partial thickness flap along the tip of the unerupted tooth. A vertical releasing incision is made on either side of the bulged crown of the impacted tooth, ensuring adequate vascularity of the elevated flap. When necessary, osteoplasty may be performed to expose the clinical crown and smooth the marginal bone covering the tooth. The flap is then api- cally positioned and sutured.

2) Closed technique

A full-thickness mucoperiosteal flap is elevated and reflected to uncover the impacted tooth. This is usually followed by bone removal to expose the clinical part of the crown. Orthodontic traction tools, such as brackets/attachment/buttons along with a ligature wire, are then bonded to the crown. This wire passes through or under the flap in the desired direction. (Fig. 1. A) Next, the flap is placed back into the original position and sutured.(Fig. 1. B) Orthodontic traction is initiated in the next stage to drag the tooth into normal occlusion.

\section{Impacted central and lateral incisors}

Delayed eruption of maxillary incisors also affects individual facial esthetics and phonetics, and is believed to occur due to permanent tooth agenesis. The incidence of impacted maxillary lateral incisors is $2.2 \%{ }^{11}$, making it the second or third most common occurrence of impaction in the dentition. On the other hand, there is a prevalence of $0.00 \%-0.01 \%$ for a missing central incisor ${ }^{12}$.

Several reports mention the main cause of delayed maxillary incisor eruption as the presence of a supernumerary tooth, with a higher frequency in the maxilla ${ }^{13,14}$. Certain syndromes are closely associated with supernumerary teeth when compared with the general population. Some studies have proposed that eruption delay can occur as a result of influential factors, for instance, the shape and position of a supernumerary tooth, which acts as a guide for the eruption of the incisors ${ }^{15}$. The tuberculate, or invaginated, type of supernumerary tooth was found to lead to more instances of delayed eruption of the maxillary incisors ${ }^{13}$. Tay et al. ${ }^{16}$ stated that the vertical position of supernumerary teeth is more likely to cause the delayed eruption of permanent incisors. Tooth malformation or dilacerations usually occur after

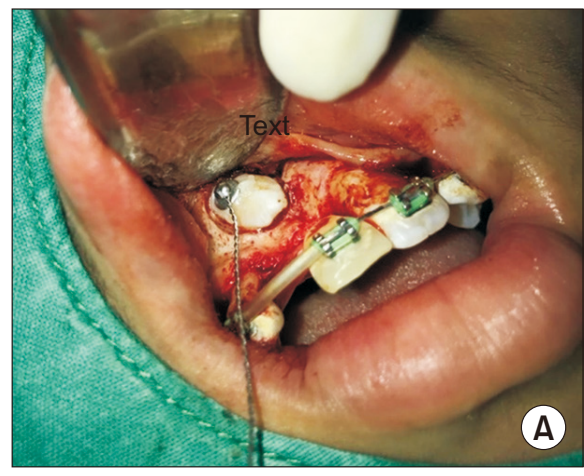

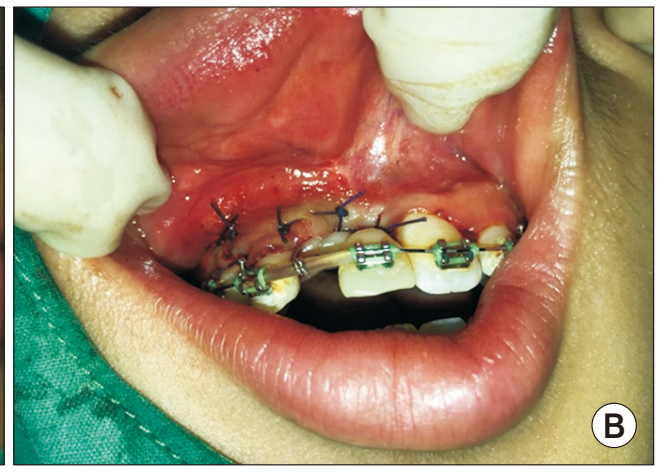

(B)
Fig. 1. Closed eruption technique. A. Surgical exposure of the canine and placement of orthodontic button. B. Flap closure into the original position. Basel Mahardawi et al: Judgement in artificial eruption of embedded teeth from an oral surgery perspective: review article. J Korean Assoc Oral Maxillofac Surg 2020 
primary tooth trauma, resulting in an injury to the developing permanent tooth bud which can lead to eruption failure. Moreover, developmental cysts or other pathologies can hinder the pathway of the developing permanent incisor ${ }^{13}$. The most common developmental lesion found in the anterior maxilla is the dentigerous cyst ${ }^{17}$. Treatment planning for an impacted incisor engulfed by a cyst ought to follow a conservative approach, as tooth preservation in young patients must be the primary concern. Therefore, marsupialization is the treatment of choice as it is atraumatic and may prevent psychological or mental stress. When there is a prolonged and retained primary incisor, it can affect the underlying developing permanent incisor, altering the pathway of eruption, even sometimes preventing it from eruption, which might be due to the formation of dense mucoperiosteum or submucosa that will form a physical eruption barrier ${ }^{18}$.

A variety of treatment procedures for unerupted maxillary incisors are proposed in the literature; however, successful outcome of treatment is best achieved with early diagnosis and prompt treatment planning ${ }^{11}$. The most conservative treatment procedure would be the extraction of any obstruction (i.e., supernumerary or deciduous tooth), followed by the creation of space, therefore creating an opportunity for spontaneous eruption. This is successful in $54 \%-74 \%$ of cases without any further treatment ${ }^{19}$.

Impacted central and lateral incisors can be managed in three divided phases. Pre-surgical orthodontic measures first create sufficient space for the unerupted tooth, and any obstructions, mainly supernumerary teeth, are removed. This is followed by surgical uncovering of the impacted tooth by either the open technique (gingivectomy or apically displaced flap) or closed technique. Orthodontic traction and alignment in the post-surgical orthodontic phase complete the treatment ${ }^{20}$. Whenever an unerupted incisor is associated with a considerable pathology, has any chance of damaging the adjacent teeth and causing resorption, or is severely ectopic, extraction of the unerupted tooth is advocated ${ }^{21}$.

\section{Impacted premolars}

Although the prevalence of premolar impaction is low, a review published by Tieu et al. ${ }^{22}$ in 2013 proposed that impaction of premolars may be caused due to prolonged ankyloses and delayed exfoliation of primary molars. In addition, some studies showed a higher predilection in the mandible than the maxilla ${ }^{23,24}$. Nevertheless, the number of cases is limited. Although the etiology of ankylosis is not well understood ${ }^{25,26}$, possibilities include genetic predisposition ${ }^{27,28}$, excessive masticatory pressure ${ }^{29}$, and disturbance in local metabolism ${ }^{30}$. Tieu et al. ${ }^{22}$ suggested that as a first step, ankylosed primary molars should undergo close observation for up to six months. A mild to moderate progressive infraocclusion will often occur along with ankylosed primary molars. Extraction of the permanent tooth may become the only option if it has an altered eruption pathway, if the infraocclusion of the ankylosed primary molar becomes severe in relation with the adjacent teeth preventing the successor from erupting, or if both conditions exist. Nonetheless, as mentioned before, conservative observation of ankylosed primary molars is suggested ${ }^{22}$.

\section{Complications of Treatment}

When making the decision to perform any surgical procedure for young children, the psychological consequences of the treatment must be considered. A 2005 study $^{31}$ to determine patient cognizance during the recovery period following the closed eruption technique indicated that the surgical procedure used to uncover the impacted tooth will likely have an adverse impact on various aspects of patient healthrelated quality of life, regardless of the technique performed. Recovery should be expected within three days postoperatively, and patients should be able to return to school within four to six days. It was found that surgery longer than thirty minutes consequently led to intensified post-operative pain. Furthermore, it was shown that the surgical uncovering of bucally impacted teeth requires a longer recovery period than palatally impacted ones ${ }^{31}$.

Choosing an appropriate flap design preceding the surgical procedure is vital. The benefits of the apically positioned flap design are in providing a sufficient band of attached gingiva that will surround the crown of the erupted tooth and in employing coronal tension when suturing. This initiates a spontaneous eruption of the incisor in the occlusal direction. This flap permits manipulation of the size of post-operative keratinized gingiva, which plays a role in saving the mucogingival complex surrounding the surgically uncovered tooth $^{32}$, ensuring a healthy long-term periodontal prognosis of the exposed and erupted tooth.

However, this flap design may be associated with poor esthetics, causing more crown length as well as gingival scarring $^{12,33}$. The clinician may choose another procedure, such as the closed eruption technique, as a result of the anterior position of canines or incisors, in an attempt to eliminate these issues. 
Damage to the adjacent teeth is another possible obstacle which can occur during surgical procedures ${ }^{17}$, and this can lead to future problems for the patient.

Moreover, periodontal complications may manifest after surgical treatment. These can include a decrease in the amount of keratinized gingiva, recession, and poor oral hygiene during the orthodontic phase. Periodontal problems are more common with buccally positioned unerupted teeth than with palatally displaced ones ${ }^{34}$. The aim of any procedure that involves mucogingival tissue intervention should ensure an adequate thickness of keratinized gingiva, thus eliminating any chance of gingival recession.

\section{Risks if No Treatment}

Leaving an impacted tooth untreated can lead to several problems including esthetic, functional, and pathological complications. Cyst formation, ankylosis, external tooth resorption, and periodontal problems can all result from untreated impacted teeth. In addition, a prolonged period of having an edentulous space might facilitate migration of distal teeth in a mesial direction, causing obliteration of space ${ }^{35}$.

There is also an association between having an impacted central incisor and the occurrence of ipsilateral canine impaction which the clinician should be aware of to prevent any such effect ${ }^{36}$.

Individuals facing the problem of impacted teeth are usually in a growing period of mixed dentition; therefore, children may face social and psychological difficulties with unpleasant tooth alignment, especially in the areas visible when smiling. Considering these points, this problem might create a negative outcome if not treated. Thus, individuals at this period must be treated properly, and any of the possible drawbacks of having an impacted tooth should be eliminated.

\section{Discussion}

Artificial eruption for impacted teeth is a procedure that relies on many factors, as well as experience, in order to choose the proper treatment option. Reviewing the literature, it is noticeable that there is still no complete consensus regarding the best technique or an absolute procedure for each type or degree of impaction. Taking the impacted maxillary canine for instance, a review published by Counihan et al. ${ }^{37}$ concluded that when the canine doesn't overlap the lateral incisor, the crown is between the CEJ (cemento-enamel junction) and half of the root length, the angulation of the canine is between $0^{\circ}-15^{\circ}$, and the apex of its root is in the normal position mesio-distally, then the treatment of choice would be only the extraction of the deciduous canine and letting the permanent tooth erupt by itself. This was also stated by Jacobs $^{38}$, who recommended that in Class I occlusion cases, with a permanent impacted maxillary canine, or when it has erupted buccally or palatally but no crowding is present, the preventive treatment of choice should be the extraction of the deciduous canine between the ages of 10-13 years. In addition, Ericson and $\mathrm{Kurol}^{39}$ treated patients 10-13 years old, and showed that the extraction of the primary canine in 46 cases of palatally impacted maxillary canine led to normalizing its position in 36 of those cases within a 12-month follow-up period, explaining that $91 \%$ of the canines which overlapped the roots of the adjacent lateral incisor root by less than half of the root (on the x-rays) moved back to the normal position, and $64 \%$ of the cases where the canine overlapped the lateral incisor by more than half of the root width initially normalized. Consequently, even when the impacted canine overlaps the lateral incisor, it is still possible to get it to the normal position with interceptive treatment only. On the other hand, the previously mentioned procedure was not in agreement with other opinions. Kinaia et al. ${ }^{40}$ indicated in their review that when the position of the impacted canine is labial (no overlapping), the crown is coronal to the muco-gingival junction (between the CEJ and half of the root length), and it is in the normal position mesio-distally, then the treatment of choice is gingivectomy followed by placing the bracket to drag the tooth orthodontically. They were not content with the interceptive treatment only, even in the simplest cases of impaction, and presented gingivectomy, apically positioned flap, and the closed technique as treatment options. They stated in this review that when the impacted canine is positioned mesially to the lateral incisor, the proper treatment would be the closed technique. This, in turn, was not consistent with Kokich $^{41}$, who suggested that in the previously mentioned case, closed eruption or excisional uncovering (gingivectomy) would not be advised. Additionally, Yordanova et al. ${ }^{42}$ treated 3 cases of palatal impaction with the open technique, which is not recommended by Kinaia et al. ${ }^{40}$ in such cases. Furthermore, Londhe et al. ${ }^{43}$ compared the open technique (gingivectomy) and closed technique for the treatment of labially impacted canines. Patients were selected randomly for each technique. They reported success in all of their cases, and their results were in favor of the closed technique in the case of labial impactions, which is not in consensus with the previously mentioned literature. 
In addition, the proper age for diagnosing tooth impaction is still uncertain. Ericson and $\mathrm{Kurol}^{44}$ explained that resorption and pathology have a higher incidence in female patients over 14 years old, and in cases with an angulation of more than 25 degrees of the canine in relation to the midline. Shi et al. ${ }^{45}$ stated that in the case of having impacted maxillary incisors by the age of 12 years, the maxillary incisor roots are fully developed already, and are dilacerated. Therefore, extraction is the only option for a successful outcome. They found that the best results were achieved with the following factors:

1) No more than two-thirds of the entire root length of the impacted tooth is formed.

2) The patient's age is between 7 and 8 years. However, the mean age of the patients in their study was 6.4-10.4 years old, and all cases were successful.

Moreover, deciding when to carry out the treatment, and the age that will result in the most successful results, is not clearly defined. Kinaia et al. ${ }^{40}$ presented 4 cases of impacted canines. The patients' ages were 12 years old in 3 cases and 15 years old in 1 case. No reports of failure or complications were shown. Londhe et al. ${ }^{43}$ treated 31 patients aged between 14-30 years old with maxillary impacted canines. Patients had undergone surgery using a closed or open technique after random selection. All cases were successful. Yordanova et al. ${ }^{42}$ presented 3 cases with palatal canine impactions. Patients' ages were 13, 15, and 20 years old. They were all treated using the open technique as mentioned earlier, with successful outcomes. Shetty el al. ${ }^{46}$ reported a case of an 11-year-old patient who had an impacted left central incisor, lateral incisor, and canine. An apically positioned flap was done to expose the impacted canine, while the closed technique was chosen for the impacted central and lateral incisors. The treatment was successful and no complications were reported.

On the other hand, Chaushu and Chaushu ${ }^{47}$ showed in their case reports that failure occurred in 2 cases where the patients were 14 and 19 years old. In two other cases, the patients were 22 and 26 years old, yet they were both successful. Chaushu and Chaushu ${ }^{47}$ indicated that the proper treatment procedure is an important factor that has a significant impact on the outcome.

As mentioned previously, Shi et al. ${ }^{45}$ conducted their study on the treatment of impacted maxillary incisors. Fifty patients aged between 6.4 and 10.4 years old were included, and all were treated successfully.

Concerning impacted premolars, Burch et al. ${ }^{48}$ performed artificial eruption on 4 patients aged 11, 12, 9, and 9 years old who had unerupted premolars. Interceptive treatment only was done, and no surgical procedure was performed to expose the impacted premolar and place an orthodontic appliance. All of the cases were successful, and no failure was outlined. A summary of all previously mentioned studies is shown in Table $1^{40,42,43,45-48}$.

\section{Conclusion}

The process of artificial eruption for an impacted tooth is an art that requires the participation of a team, not just an orthodontist. Therefore, the authors would like to emphasize that what matters most is moving the impacted tooth into normal occlusion and having well-aligned teeth in the end, regardless of the technique used. The authors did not suggest criteria or recommend any technique as the debate on which to use in specific cases is ongoing. After reviewing the literature, it is clear that there is no absolute indication for each technique for exposing an impacted tooth, and it is mainly dependent upon experience and preference. In addition, there is no exact evidence on the proper age for the diagnosis and treatment of impacted teeth, but obviously the younger the patient is the better the prognosis. Needless to say, a precise

Table 1. Techniques to expose impacted teeth and treatment outcome in the literature

\begin{tabular}{|c|c|c|c|c|c|}
\hline Study & $\begin{array}{c}\text { Age of each patient or } \\
\text { age range }(y r)\end{array}$ & Tooth & Type of impaction & Technique & Success/failure \\
\hline Burch et al. $^{48}$ (1994) & $11 / 12 / 9 / 9$ & Premolar & N/A & Interceptive & Success \\
\hline \multirow{2}{*}{ Chaushu and Chaushu $^{47}$ (2010) } & 14-19 & Canine & Labial & N/A & Failure \\
\hline & $22-26$ & Canine & Palatal & N/A & Success \\
\hline Yordanova et al. $^{42}$ (2011) & $13 / 15 / 20$ & Canine & Palatal & Open & Success \\
\hline Londhe et al. $^{43}$ (2014) & $14-30$ & Canine & Labial & Closed+open & Success \\
\hline Shetty el al. ${ }^{46}(2015)$ & 11 & Canine & N/A & Open+closed & Success \\
\hline Shi et al. ${ }^{45}(2015)$ & $6.4-10.4$ & Incisor & N/A & Closed & Success \\
\hline Kinaia et al. $^{40}(2016)$ & $12 / 12 / 15 / 12$ & Canine & $\begin{array}{l}\text { Buccal+palatal+ } \\
\text { mid alveolar }\end{array}$ & Open+closed & Success \\
\hline
\end{tabular}

(N/A: not available)

Basel Mahardawi et al: Judgement in artificial eruption of embedded teeth from an oral surgery perspective: review article. J Korean Assoc Oral Maxillofac Surg 2020 
diagnosis and a thoughtful choice of treatment modality is essential for an acceptable outcome regardless of age.

Nevertheless, it would be of great benefit to set more accurate touchstones concerning the proper age for diagnosing and treating impacted teeth, as well as the most advisable technique for every type of impaction. Further studies and analysis may provide more information about the previously mentioned suggestions and clarify the criteria and standards of treatment, consequently delivering more predictable outcomes and higher success rates in the future.

\section{ORCID}

Basel Mahardawi, https://orcid.org/0000-0001-5113-535X

Kumar K C, https://orcid.org/0000-0001-9620-7388

Kanin Arunakul, https://orcid.org/0000-0002-8710-443X

Teeranut Chaiyasamut, https://orcid.org/0000-0003-0487-5333

Natthamet Wongsirichat, https://orcid.org/0000-0003-3005-2680

\section{Authors' Contributions}

B.M. wrote the abstract, introduction and discussion, and corrected the language of the article as a whole. K.K C wrote the chapters about each impacted tooth, the complications, and the risk if no treatment. K.A. provided the idea to be discussed (in the discussion part). T.C. provided the clinical case with the photograph, as well as the consultation regarding the surgical procedure. N.W. guided through the entire process, arranging the article as a whole, and going through the process for publication.

\section{Acknowledgements}

The authors would like to thank the staff and dental assistants, including colleagues and co-workers, in the Department of Oral and Maxillofacial Surgery, Faculty of Dentistry, Mahidol University.

\section{Ethics Approval and Consent to Participate}

This study is a review article with no need for ethics approval.

\section{Conflict of Interest}

No potential conflict of interest relevant to this article was reported.

\section{References}

1. Almonaitiene R, Balciuniene I, Tutkuviene J. Factors influencing permanent teeth eruption. Part one--general factors. Stomatologija 2010;12:67-72.

2. Takahama Y, Aiyama Y. Maxillary canine impaction as a possible microform of cleft lip and palate. Eur J Orthod 1982;4:275-7.

3. Sacerdoti R, Baccetti T. Dentoskeletal features associated with unilateral or bilateral palatal displacement of maxillary canines. Angle Orthod 2004;74:725-32.

4. Dachi SF, Howell FV. A survey of 3,874 routine full-mouth radiographs. I. A study of retained roots and teeth. Oral Surg Oral Med Oral Pathol 1961;14:916-24.

5. Johnston WD. Treatment of palatally impacted canine teeth. Am J Orthod 1969;56:589-96.

6. Rimes RJ, Mitchell CN, Willmot DR. Maxillary incisor root resorption in relation to the ectopic canine: a review of 26 patients. Eur J Orthod 1997;19:79-84.

7. Pinho T, Neves M, Alves C. Impacted maxillary central incisor: surgical exposure and orthodontic treatment. Am J Orthod Dentofacial Orthop 2011;140:256-65.

8. Mathews DP, Kokich VG. Palatally impacted canines: the case for preorthodontic uncovering and autonomous eruption. Am J Orthod Dentofacial Orthop 2013;143:450-8.

9. Andreasen GF. A review of the approaches to treatment of impacted maxillary cuspids. Oral Surg Oral Med Oral Pathol 1971;31:47984.

10. Berglund L, Kurol J, Kvint S. Orthodontic pre-treatment prior to autotransplantation of palatally impacted maxillary canines: case reports on a new approach. Eur J Orthod 1996;18:449-56.

11. Vastardis $\mathrm{H}$. The genetics of human tooth agenesis: new discoveries for understanding dental anomalies. Am J Orthod Dentofacial Orthop 2000;117:650-6.

12. Polder BJ, Van't Hof MA, Van der Linden FP, Kuijpers-Jagtman AM. A meta-analysis of the prevalence of dental agenesis of permanent teeth. Community Dent Oral Epidemiol 2004;32:217-26.

13. Bodenham RS. The treatment and prognosis of unerupted maxillary incisors associated with the presence of supernumerary teeth. Br Dent J 1967;123:173-7.

14. Munns D. Unerupted incisors. Br J Orthod 1981;8:39-42.

15. Garvey MT, Barry HJ, Blake M. Supernumerary teeth--an overview of classification, diagnosis and management. J Can Dent Assoc 1999;65:612-6.

16. Tay F, Pang A, Yuen S. Unerupted maxillary anterior supernumerary teeth: report of 204 cases. ASDC J Dent Child 1984;51:289-94.

17. Mueller-Lessmann V, Behrendt A, Wetzel WE, Petersen K, Anders D. Orofacial findings in the Klippel-Trénaunay syndrome. Int J Paediatr Dent 2001;11:225-9.

18. Jones JW, Husain J. Management of the unerupted incisor. Dent Update 1996;23:36-9.

19. Kramer RM, Williams AC. The incidence of impacted teeth. A survey at Harlem hospital. Oral Surg Oral Med Oral Pathol 1970;29:237-41.

20. Oliver RG, Hardy P. Practical and theoretical aspects of a method of orthodontic traction to unerupted teeth illustrated by three cases. Br J Orthod 1986;13:229-36.

21. Rose JS, Cannell H. Treatment of an inverted unerupted central incisor. Br Dent J 1975;138:325.

22. Tieu LD, Walker SL, Major MP, Flores-Mir C. Management of ankylosed primary molars with premolar successors: a systematic review. J Am Dent Assoc 2013;144:602-11.

23. Sandeepa NC, Ajmal M, Deepika N. A retrospective panoramic radiographic study on prevalence of impacted teeth in South Karnataka population. J Oral Hyg Health 2016;4:197.

24. Mustafa AB. Prevalence of impacted pre-molar teeth in College of Dentistry, King Khalid University, Abha, Kingdom of Saudi Arabia. J Int Oral Health 2015;7:1-3. 
25. Messer LB, Cline JT. Ankylosed primary molars: results and treatment recommendations from an eight-year longitudinal study. Pediatr Dent 1980;2:37-47.

26. Kurol J, Thilander B. Infraocclusion of primary molars with aplasia of the permanent successor. A longitudinal study. Angle Orthod 1984;54:283-94.

27. Kurol J. Infraocclusion of primary molars: an epidemiologic and familial study. Community Dent Oral Epidemiol 1981;9:94-102.

28. Via WF Jr. Submerged deciduous molars: familial tendencies. J Am Dent Assoc 1964;69:127-9.

29. Adamson KT. The problem of impacted teeth in orthodontics. Aust Dent J 1952;56:74-84.

30. Bjerklin K, Kurol J. Prevalence of ectopic eruption of the maxillary first permanent molar. Swed Dent J 1981;5:29-34.

31. Chaushu S, Becker A, Zeltser R, Branski S, Vasker N, Chaushu G. Patients perception of recovery after exposure of impacted teeth: a comparison of closed- versus open-eruption techniques. J Oral Maxillofac Surg 2005;63:323-9.

32. Ong M, Chew MT. Use of the apically repositioned flap in the management of labially impacted maxillary central incisors. Singapore Dent J 2004;26:55-9.

33. Kajiyama K, Kai H. Esthetic management of an unerupted maxillary central incisor with a closed eruption technique. Am J Orthod Dentofacial Orthop 2000;118:224-8.

34. Kavadia-Tsatala S, Tsalikis L, Kaklamanos EG, Sidiropoulou S, Antoniades K. Orthodontic and periodontal considerations in managing teeth exhibiting significant delay in eruption. World J Orthod 2004;5:224-9.

35. Grover PS, Lorton L. The incidence of unerupted permanent teeth and related clinical cases. Oral Surg Oral Med Oral Pathol 1985;59:420-5.

36. Chaushu S, Zilberman Y, Becker A. Maxillary incisor impaction and its relationship to canine displacement. Am J Orthod Dentofacial Orthop 2003;124:144-50; discussion 150.

37. Counihan K, Al-Awadhi EA, Butler J. Guidelines for the assessment of the impacted maxillary canine. Dent Update 2013;40:770$2,775-7$.

38. Jacobs SG. Reducing the incidence of palatally impacted maxillary canines by extraction of deciduous canines: a useful preventive/interceptive orthodontic procedure. Case reports. Aust Dent J
1992;37:6-11.

39. Ericson S, Kurol J. Early treatment of palatally erupting maxillary canines by extraction of the primary canines. Eur J Orthod 1988;10:283-95.

40. Kinaia BM, Agarwal K, Bushong B, Kapoor N, Hope K, Ambrosio $\mathrm{F}$, et al. Surgical management of impacted canines: a literature review and case presentations. J Dent Oral Biol 2016;1:1012.

41. Kokich VG. Surgical and orthodontic management of impacted maxillary canines. Am J Orthod Dentofacial Orthop 2004;126:278-83.

42. Yordanova M, Yordanova S, Vladimirov B. Surgical uncovering and stimulation of physiological eruption of palatally impacted maxillary canines: case reports. J IMAB 2011;17:114-9.

43. Londhe SM, Kumar P, Datana S, Kotwal A, Saxena V. Guided tooth eruption: comparison of open and closed eruption techniques in labially impacted maxillary canines. J Dent Res Rev 2014;1:14851.

44. Ericson S, Kurol J. Incisor resorption caused by maxillary cuspids. A radiographic study. Angle Orthod 1987;57:332-46.

45. Shi XR, Hu Z, Wang XZ, Sun XY, Zhang CY, Si Y, et al. Evaluation of the effect of the closed-eruption technique on impacted immature maxillary incisors. Chin J Dent Res 2015;18:111-5.

46. Shetty BK, Somaiah S, Muddaiah S, Parveen S, Sirajuddin. Guided eruption of multiple impacted teeth using a modified miniplate. J Clin Orthod 2015;49:273-80.

47. Chaushu S, Chaushu G. Skeletal implant anchorage in the treatment of impacted teeth: a review of the state of the art. Semin Orthod 2010;16:234-41.

48. Burch J, Ngan P, Hackman A. Diagnosis and treatment planning for unerupted premolars. Pediatr Dent 1994;16:89-95.

How to cite this article: Mahardawi B, K C K, Arunakul K, Chaiyasamut T, Wongsirichat N. Judgement in artificial eruption of embedded teeth from an oral surgery perspective: review article. J Korean Assoc Oral Maxillofac Surg 2020;46:12-18. https://doi. org/10.5125/jkaoms.2020.46.1.12 